\title{
Alfalfa Plants (Medicago sativa L.) Expressing the 85B (MAP1609c) Antigen of Mycobacterium avium subsp. paratuberculosis Elicit Long-Lasting Immunity in Mice
}

\author{
Elizabeth Monreal-Escalante ${ }^{1,2,3} \cdot$ Cristhian Sández-Robledo ${ }^{1} \cdot$ Amalia León-Gallo $^{3}$. Virginie Roupie ${ }^{4}$ Kris Huygen $^{5}$. \\ Sawako Hori-Oshima ${ }^{6} \cdot$ Mario Arce-Montoya $^{1} \cdot$ Sergio Rosales-Mendoza ${ }^{3} \cdot$ Carlos Angulo $^{1} \mathbb{}$
}

Received: 29 July 2020 / Accepted: 12 February 2021 / Published online: 2 March 2021

(c) The Author(s), under exclusive licence to Springer Science+Business Media, LLC part of Springer Nature 2021

\begin{abstract}
Mycobacterium avium subsp. paratuberculosis (MAP) is the etiological agent of Paratuberculosis, a contagious, untreatable, and chronic granulomatous enteritis that results in diarrhea, emaciation, and death in farmed ruminants (i.e., cattle, sheep, and goats). In this study, the Ag85B antigen from MAP was expressed in transgenic alfalfa as an attractive vaccine candidate. Agrobacterium-mediated transformation allowed the rescue of 56 putative transformed plants and transgenesis was confirmed in 19 lines by detection of the Ag85B gene (MAP1609c) by PCR. Line number 20 showed the highest Ag85B expression [840 ng Ag85B per gram of dry weight leaf tissue, 0.062\% Total Soluble Protein (TSP)]. Antigenicity of the plant-made Ag85B was evidenced by its reactivity with a panel of sera from naturally MAP-infected animals, whereas immunogenicity was assessed in mice immunized by either oral or subcutaneous routes. The plant-made Ag85B antigen elicited humoral responses by the oral route when co-administered with cholera toxin as adjuvant; significant levels of anti-85B antibodies were induced in serum (IgG) and feces (IgA). Long-lasting immunity was evidenced at day 180 days post-first oral immunization. The obtained alfalfa lines expressing Ag85B constitute the first model of a plant-based vaccine targeting MAP. The initial immunogenicity assessment conducted in this study opens the path for a detailed characterization of the properties of this vaccine candidate.
\end{abstract}

Keywords Paratuberculosis $\cdot 85 \mathrm{~B}$ antigen $\cdot$ Plant-made vaccine $\cdot$ Alfalfa $\cdot$ Oral vaccine

Elizabeth Monreal-Escalante and Cristhian Sández-Robledo have contributed equally to this work.

Sergio Rosales-Mendoza

rosales.s@uaslp.mx

$\triangle$ Carlos Angulo

eangulo@cibnor.mx

1 Immunology and Vaccinology Group, Centro de Investigaciones Biológicas del Noroeste, SC, Instituto Politécnico Nacional, 195, Playa Palo de Santa Rita Sur, La Paz, Baja California Sur 23096, Mexico

2 CONACYT-Centro de Investigaciones Biológicas del Noroeste (CIBNOR), Instituto Politécnico Nacional, 195, Playa Palo de Santa Rita Sur, La Paz, Baja California Sur 23096, Mexico

3 Facultad de Ciencias Químicas, Universidad Autónoma de San Luis Potosí, Av. Dr. Manuel Nava Num. 6, Zona Universitaria., San Luis Potosí, San Luis Potosi 78210, Mexico
4 Veterinary and Agrochemical Research Institute, VAR-CODA-CERVA, 1180 Brussels, Belgium

5 Scientific Service Immunology, Scientific Institute of Public Health WIV-ISP (Site Ukkel), 642 Engelandstraat, 1180 Brussels, Belgium

6 Instituto de Investigaciones en Ciencias Veterinarias, Universidad Autónoma de Baja California, Carretera San Felipe Km. 3.5, Fraccionamiento Laguna Campestre, Mexicali, Baja California 21387, Mexico 


\section{Introduction}

During the last decades molecular farming has led to the development of new platforms that positively impact the production of biopharmaceuticals [1]. Currently, plants have proven to be excellent biofactories for the production of vaccines in various platforms, including whole plants grown in soil or in hydroponic systems (stably or transiently transformed), cell suspension cultures, and hairy roots cultivated in vitro [2,3]. Plants have numerous advantages for biopharmaceuticals' production compared to prokaryotic or other eukaryotic systems, such as (1) reduced contamination risks, (2) reduced costs, (3) easy scale-up, (4) capability to synthesize large functional proteins requiring complex post-translational modifications, and (5) the ability to serve as safe and effective oral delivery vehicles $[2,4]$. Regarding the latter aspect, the plant cell mediates bio-encapsulation of the antigen, protecting it from digestive enzymes and enhancing the induced immune response by a gradual release of the antigen and providing compounds with mucoadhesive or adjuvant properties [5, 6]. Moreover, the production of plant-made vaccines is a promising strategy to overcome the high vaccination costs in low-income countries [7].

Among the plant species used in this field, alfalfa has been used in multiple studies for the production of oral plant-based vaccines, showing proper immunogenicity and significant protection against experimental challenges with the pathogen [8-16]. As nutritive forage, alfalfa is an attractive edible plant to formulate oral vaccines for animals such as ruminants, which are affected by numerous gastrointestinal infectious diseases. Thus, dairy and meat cattle, sheep, and goats could be orally vaccinated with alfalfa biomass containing protective antigens against intestinal diseases. In this context, Mycobacterium avium subsp. paratuberculosis (MAP) is a relevant target since this pathogen causes important losses in milk and meat production worldwide, affecting farmed ruminants (i.e., cattle, sheep, and goats) [17].

MAP is the etiological agent of Johne's Disease (JD, also known as Paratuberculosis), a contagious, untreatable, and typically fatal chronic granulomatous enteritis that results in profuse diarrhea, emaciation and eventually death [18]. It has been shown that MAP is subjected to phagocytosis and survives within subepithelial macrophages where it remains hidden from the immune system [19]. Currently, three commercial vaccines based on inactivated whole bacteria are available, namely Mycopar®, Gudair ${ }^{\circledR}$, and Silirum. Although these vaccines confer partial protection, reduce bacterial shedding, and decrease the severity of the disease [20]; they cause side effects, such as lesions attributed to strong inflammatory reactions that can impact the economic value of meat carcass; crossreaction with other mycobacterial diseases; and chronic abscesses developed by farmers accidentally inoculated with the vaccine [21, 22].

To overcome the limitations of the conventional vaccines, multiple MAP antigens have been assessed for their immunogenicity and immunoprotective potential. Several subunit vaccines against tuberculosis are currently under clinical evaluation, with Antigen 85B (Ag85B) as one of the most promising [23]. Ag85B belongs to the Antigen 85 Complex (Ag85A, Ag85B and Ag85C), which is the most abundant secreted and highly conserved set of proteins with mycolyl-transferase activity in Mycobacteria [24]. Interestingly, MAP-Ag85B has been evaluated as vaccine antigen in mice using DNA vaccines and recombinant subunit vaccines, showing satisfactory results in terms of immunogenicity and reduction of bacterial burden [24-29]. Moreover, Ag85B from Mycobacterium tuberculosis has been expressed in plants rendering an immunogenic protein that is immunogenic in mice [30-32]. Other M. tuberculosis antigens produced in plants, such as ESAT-6 [33-37] and Mtb72F and LipY from M. tuberculosis [38] are promising candidates.

Surprisingly, no studies on the development of plantmade vaccines against Mycobacterium avium subsp. paratuberculosis have been reported thus far. In this study, MAP-Ag85B was expressed in alfalfa plants and its immunogenicity evaluated in test mice upon oral and subcutaneous administration. Immunization schemes were designed to determine the effect of a mucosal adjuvant on the humoral response as well as studying the long-lasting immunity induced by the plant-made antigen.

\section{Materials and Methods}

\section{Plant Materials}

Medicago sativa L. (RSY27) cultures were kindly donated by Sandra Austin-Phillips from the Biotechnology Plant Laboratory, Wisconsin University, USA. Plants were cultured as described by Samac and Austin-Phillips [39]. Briefly, in vitro stock plants were maintained on Murashige and Skoog medium (MS0) in Magenta GA7 vessels. To subculture plants, shoot pieces $(0.5 \mathrm{~cm})$ with three to four nodes were transferred into agar-solid MS0 medium. Cultures were maintained at $25^{\circ} \mathrm{C}$ under a $16 \mathrm{~h}$ light and $8 \mathrm{~h}$ dark photoperiod (of 60 to $80 \mu \mathrm{E} / \mathrm{m} 2 / \mathrm{s}$ ). Regenerated plants were transferred to a mixture of soil and vermiculite $(1: 1)$ and grown in a greenhouse at $21^{\circ} \mathrm{C}$ with $30 \%$ of relative humidity and a $16 \mathrm{~h}$ light photoperiod with a light intensity of $100 \mu \mathrm{mol} \mathrm{m}{ }^{-2} \mathrm{~s}^{-1}$. 


\section{DNA Construct}

The gene coding for MAP-Ag85B (831 bp, MAP1609c) was previously obtained from MAP ATCC 19,698 strain and cloned into pQE80L [26]. Then, MAP-Ag85B gene was amplified from the construct pQE80L::Ag85B using the following primers: sense $5^{\prime}$ TTTTCTAGAATGGGC CGCGACATCAAGGTC $3^{\prime}$ and antisense 5' TTTTCTAGA AGTTATCCGCCGCCGCCCG 3'. The amplification protocol comprised: $95{ }^{\circ} \mathrm{C}$ for 3 min for initial denaturation; 35 cycles comprising the next steps: $95^{\circ} \mathrm{C}$ for $1 \mathrm{~min}, 60^{\circ} \mathrm{C}$ for $1 \mathrm{~min}, 72{ }^{\circ} \mathrm{C}$ for $1 \mathrm{~min}$; and a final extension at $72{ }^{\circ} \mathrm{C}$ for $10 \mathrm{~min}$. The amplicon was cloned into the $\mathrm{pCR} \circledast 8 / \mathrm{GW} /$ TOPO vector following manufacturer's instructions (Invitrogen, ThermoFisher Scientific, Waltham, MA, USA). Subsequently, pCR®8/GW/TOPO::Ag85B was subjected to a final recombination with LR Clonase II to generate the pMDC32::Ag85B construct. The reaction was performed following manufacturer's recommendation for Gateway ${ }^{\mathrm{TM}}$ LR Clonase ${ }^{\mathrm{TM}}$ II Enzyme mix (Cat. 11,791,100, Invitrogen). Briefly, $150 \mathrm{ng}$ of $\mathrm{pCR} \circledast 8 / \mathrm{GW} / \mathrm{TOPO}: \mathrm{Ag} 85 \mathrm{~B}$ and $150 \mathrm{ng}$ of pMDC32 were mixed ( $8 \mu \mathrm{L}$ total volume) and incubated at $25{ }^{\circ} \mathrm{C}$ overnight. Afterwards, $1 \mu \mathrm{L}$ of proteinase $\mathrm{K}$ was added and the reaction incubated at $37{ }^{\circ} \mathrm{C}$ for $10 \mathrm{~min}$. The pMDC32::Ag85B contains a double $35 \mathrm{~S}$ CaMV promoter and the NOS terminator to drive the expression of the gene of interest and an expression cassette that confers hygromycin resistance to the transformed plants
(Fig. 1). The pMDC32::Ag85B was transferred $(\sim 2 \mu \mathrm{g})$ to Agrobacterium tumefaciens LBA4404 (50 $\mu \mathrm{l}, 5 \times 10^{10}$ cell/ $\mathrm{mL})$ by electroporation $(25 \mu \mathrm{F}, 2.5 \mathrm{kV}, 200$, Gene pulser II electroporation system Bio-Rad, Hercules, CA, USA). Transformed bacterial clones were rescued in YM medium $(0.4 \mathrm{~g} / \mathrm{L}$ yeast extract, $10 \mathrm{~g} / \mathrm{L}$ mannitol, $0.1 \mathrm{~g} / \mathrm{L} \mathrm{NaCl}, 0.1 \mathrm{~g} / \mathrm{L}$ $\mathrm{MgSO}_{2}, 0.5 \mathrm{~g} / \mathrm{L} \mathrm{K}_{2} \mathrm{HPO}_{4} \cdot 3 \mathrm{H}_{2} \mathrm{O}, \mathrm{pH}$ 7.0) containing $50 \mathrm{mg} / \mathrm{L}$ kanamycin.

\section{Alfalfa Transformation and Molecular Analysis}

Alfalfa plants transformed with the $A g 85 B$ gene were obtained by Agrobacterium-mediated transformation following the method described by Celis-García [40]. Briefly, the A. tumefaciens LBA4404 carrying the expression vector was grown in YEP medium $(10 \mathrm{~g} / \mathrm{L}$ yeast extract, $10 \mathrm{~g} / \mathrm{L}$ peptone, $5 \mathrm{~g} / \mathrm{L} \mathrm{NaCl})$ at $28-30{ }^{\circ} \mathrm{C}$ with agitation (200-300 rpm). Alfalfa leaves were cut and placed in Petri dishes containing sterile distilled water. Leaves were disinfected in $70 \%$ ethanol for 5-10 s and rinsed 3 times with distilled water. Leaves were divided in $0.5 \times 0.5 \mathrm{~cm}$ squares on a sterile Petri dish with a razor blade and transferred to $12 \mathrm{~mL}$ of SHO medium $(10 \mathrm{~g} / \mathrm{L}$ sucrose, $0.5 \mathrm{~g} / \mathrm{L}$ MES, pH 5.7). Fifteen $\mathrm{mL}$ of A. tumefaciens culture were centrifuged, and cells resuspended in $3 \mathrm{~mL}$ of $\mathrm{SHO}$, and used to inoculate leaf segments for 10-30 min. Leaf sections were subsequently transferred to Bh5 medium plates. After 1 week of co-cultivation
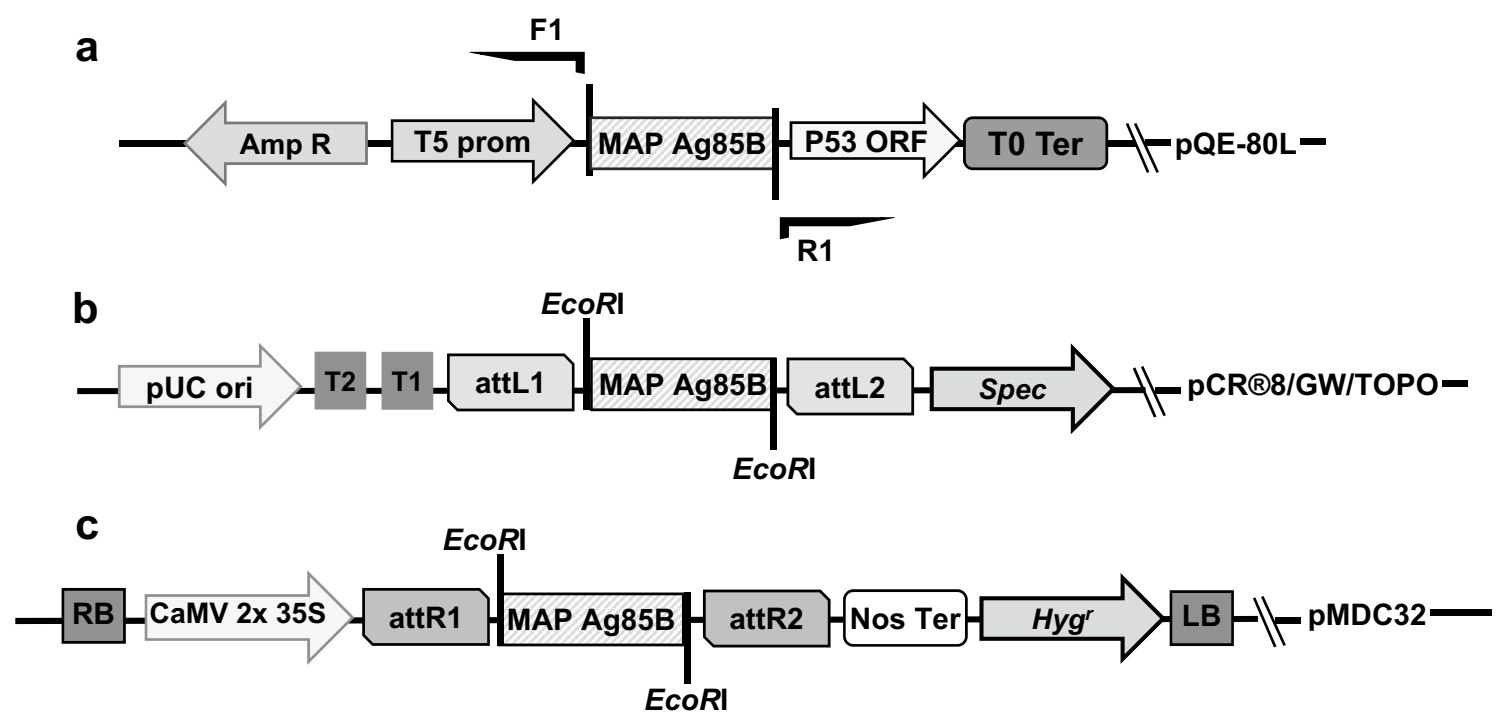

Fig. 1 Schematic representation of vectors containing cloning sites and primers locations used for the Ag85B expression in alfalfa (Medicago sativa $\mathrm{L}$.). a Map of the $\mathrm{pQE} 80 \mathrm{~L}$ vector. $\mathrm{F} 1$ and $\mathrm{R} 1$ indicate primers used for amplification Ag85B gene. b Map of pCR®8/GW/ TOPO (Invitrogen, ThermoFisher Scientific, Waltham, MA, USA). $\mathrm{Ag} 85 \mathrm{~B}$ gene was cloned into ECoRI sites and subsequently, pCR®8/
GW/TOPO::Ag85B was subjected to a final recombination with LR Clonase II to generate the pMDC32::Ag85B c Physical map of the pMDC32::Ag85B vector that allows for the stable expression in plants driven by the double $35 \mathrm{SCaMV}$ promoter and the NOS terminator, which allows expressing the gene of interest, and a gene marker that confers hygromycin resistance in the transformed plants 
explants were rinsed 3-4 times with distilled water, dried onto sterile filter paper and transferred to the selection medium B5hHyg-BCb (3.5 g/L Gamborg's salts; $1 \mathrm{ml} / \mathrm{L}$ Gamborg's vitamins solution $1000 \mathrm{X} ; 0.5 \mathrm{~g} / \mathrm{L} \mathrm{KNO}_{3}$; $0.25 \mathrm{~g} / \mathrm{L} \mathrm{MgSO}_{4}\left(7 \mathrm{H}_{2} \mathrm{O}\right) ; 0.5 \mathrm{~g} / \mathrm{L}$ proline; $30 \mathrm{~g} / \mathrm{L}$ sucrose; $8 \mathrm{~g} / \mathrm{L}$ agar; $1 \mathrm{mg} / \mathrm{L} \mathrm{2,4-D;} 0.1 \mathrm{mg} / \mathrm{L}$ kinetin, $50 \mathrm{mg} / \mathrm{L}$ hygromycin; $500 \mathrm{mg} / \mathrm{L}$ carbenicillin). After 2-3 weeks cultivation in selective media, embryos were transferred to regeneration medium $\mathrm{B} 5 \mathrm{~h} 0 \mathrm{Hyg}-\mathrm{BCb}$ (same as B5hHyg$\mathrm{BCb}$ without hormones). Embryos were individualized and cultured in MMS medium (4.3 g/L Murashige-Skoog salts; $1 \mathrm{~mL} / \mathrm{L}$ Nitsch and Nitsch $1000 \mathrm{X}$ vitamins stock; $0.1 \mathrm{~g} / \mathrm{L}$ myo-Inositol; $30 \mathrm{~g} / \mathrm{L}$ sucrose; $7.6 \mathrm{~g} / \mathrm{L}$ agar, $\mathrm{pH}$ 5.7 ) with $50 \mathrm{mg} / \mathrm{L}$ hygromycin and non-growing or deformed plants were discarded.

Once plants were regenerated, a bioassay to assess the transgenesis was performed by inducing callus in selective media (B5hHyg-BCb). Briefly, leaf explants (three leaves) from each regenerated line were cut and transferred onto solid selective media $\mathrm{B} 5 \mathrm{hHyg}-\mathrm{BCb}$ and incubated as described above. Leaves from near isogenic control plants (WT) were used as negative control.

The presence of the transgene in alfalfa plants was assessed by PCR. Total DNA was extracted from alfalfa leaves following a previously described protocol by protocol [41]. PCR to amplify the $A g 85 B$ gene was performed as described above in a reaction containing GoTaq ${ }^{\circledR}$ Flexi DNA Polymerase (0.1U) (Promega, USA), $\mathrm{MgCl}_{2}(2 \mathrm{mM})$, dNTP's (0.2 mM), Fw primer $(0.8 \mu \mathrm{M})$, Rv primer $(0.8 \mu \mathrm{M})$, and DMSO (5\%).

\section{Production of Recombinant Ag85B in Escherichia coli and Hyperimmune Serum}

The expression vector pQE-80L-Ag85B [26] was used to produce Ag85B in E. coli. Cells were grown on LB-ampicillin medium (100 mg/L) and transformation was confirmed by PCR as described above. Recombinant Ag85B (rAg85B) was expressed as His-tagged protein after $4 \mathrm{~h}$ induction with IPTG and purified by affinity chromatography on immobilized nickel-chelate (Ni-NTA) column. Expression of the target protein was evidenced by $4-10 \%$ SDS-PAGE analysis.

$\mathrm{BALB} / \mathrm{c}$ mice used in this study were maintained under standard laboratory conditions with free access to food and water following the procedures indicated by the Federal Regulation for Animal Experimentation and Care (SAGARPA, NOM-062-ZOO-1999, México). Two female mice (13-week-old) were used to develop serum against purified Ag85B produced in E. coli. Mice were immunized at day 1 into the rear foot pad with $10 \mu \mathrm{g}$ of purified Ag85B emulsified in $20 \mu \mathrm{L}$ of complete Freund's adjuvant (CFA).
Three subsequent immunizations were applied intraperitoneally on days 8,15 , and 22 ; in which doses consisted of $10 \mu \mathrm{g}$ of Ag85B emulsified in one volume of incomplete Freund's adjuvant (IFA). Mice were bled on day 29 to measure antibody titers (triplicate) by ELISA. Animals were subsequently sacrificed to collect sera.

\section{Recombinant Antigen Analysis and Quantification in Plants}

Total soluble protein (TSP) extracts were obtained from freeze-dried leaves of transgenic alfalfa lines following the protocol described by Aguilar et al. [42]. The presence of the recombinant protein was assessed by ELISA and plant lines with higher production were selected and propagated in vitro. Briefly, $50 \mu \mathrm{L}$ per well of protein extracts diluted in carbonate buffer ( $\mathrm{pH}$ 9.6) were used for coating $(20 \mu \mathrm{g} / \mathrm{mL})$ during $2 \mathrm{~h}$ at $37^{\circ} \mathrm{C}$. Plates were washed three times with PBST (PBS with $0.05 \%$ Tween-20). Thereafter, skimmed milk solution $(5 \%, 200 \mu \mathrm{L})$ was added. Primary labeling was performed with sera from animals naturally infected with MAP (donated by the Autonomous University of Baja California, Mexicali, Baja California, México) to analyze immunoreactivity or hyperimmune serum against $\mathrm{Ag} 85 \mathrm{~B}$ raised in mice (1:25 or 1:1000, respectively) to quantify the produced level of plantmade-antigen. Hyperimmune serum from mice was used because animals were immunized with purified Ag85B and it allowed a better specific antibody production to quantify plant-made antigen rather than naturally infected animals. Plates were incubated at $37^{\circ} \mathrm{C}$ for $1.5 \mathrm{~h}$ and following 3 washes with PBST, $100 \mu \mathrm{L}$ of goat anti-mouse IgG HRPconjugated secondary antibody or donkey anti-goat IgG HRP-conjugated secondary antibody were added to each well and incubated at $37{ }^{\circ} \mathrm{C}$ for $1.5 \mathrm{~h}$. Plates were washed and immunodetection was revealed by adding a solution of o-Phenylenediamine dihydrochloride (OPD) peroxidase substrate (\#P8287, Sigma, St. Louis, MO). Absorbance at $490 \mathrm{~nm}$ was measured in a Microplate Reader (Model 3550-UV, Bio-Rad, Hercules, CA, USA). A standard curve made with known amounts of pure Ag85B produced in $E$. coli was included in the analysis to quantify the levels of the recombinant protein in the plant tissues. Each sample was analyzed in triplicate. In addition, Western blot analysis was conducted as described by Monreal-Escalante et al. [43] using hyperimmune sera raised in mice. Briefly, protein extracts were obtained using $1.25 \mathrm{mg}$ of freeze-dried alfalfa leaves mixed with $50 \mu \mathrm{L} 1 \mathrm{X}$ reducing NUPAGE LDS sample buffer and NUPAGE antioxidant (Invitrogen, Carlsbad, CA, USA). Protein extracts were resolved by SDS-PAGE using 4-12\% acrylamide gels under denaturing conditions and transferred to PVDF membranes $(150 \mathrm{~V}$ for $1 \mathrm{~h})$. Upon blocking with skimmed milk (5\%), 1:500 
hyperimmune serum dilution was added. Afterwards, a donkey anti-goat IgG HRP-conjugated secondary antibody $(1: 2000)$ was added and the reaction was subsequently revealed with SuperSignal West Dura solution following manufacturer's instructions (ThermoFisher Scientific, Waltham, MA, USA).

\section{Immunogenicity Evaluation}

\section{Experiment I: Oral Immunization Without Adjuvant}

Eight-week-old female BALB/c mice groups $(n=3)$ were orally (p.o.) or subcutaneously (s.c.) immunized ( $84 \mathrm{ng}$ per dose) at days $0,7,15$, and 24 , with one of the following formulations based on milled freeze-dried alfalfa leaves resuspended in PBS $(100 \mu \mathrm{L})$ : (i) $100 \mathrm{mg}$ wild type alfalfa (p.o.), (ii) $100 \mathrm{mg}$ transgenic alfalfa expressing Ag85B (p.o.), (iii) $100 \mathrm{mg}$ wild type alfalfa (s.c.), and (iv) $100 \mathrm{mg}$ transgenic alfalfa expressing Ag85B (s.c.). Subcutaneous doses consisted of soluble protein extracts obtained in PBS by sonicating alfalfa biomass and clarification by centrifugation, whereas oral doses comprise freeze-dried alfalfa leaves resuspended in PBS and administered intragastrically using a mouse cannula. Mice were bled prior to each immunization to obtain serum samples.

\section{Experiment II: Oral Immunization with Adjuvant}

Eight-week-old female BALB/c mice groups $(n=4)$ were orally immunized at days $0,7,15$, and 24 , with one of the following formulations based in milled freeze-dried alfalfa leaves resuspended in PBS $(100 \mu \mathrm{L})$ : (i) $100 \mathrm{mg}$ wild type alfalfa, (ii) $100 \mathrm{mg}$ transgenic alfalfa expressing $\mathrm{Ag} 85 \mathrm{~B}$, (iii) $100 \mathrm{mg}$ transgenic alfalfa expressing Ag85B $+10 \mu \mathrm{g}$ Cholera toxin (CT, Sigma). Mice were bled prior to each immunization to obtain serum samples.

\section{Long-Term Immunogenicity Evaluation}

Mice were boosted at 180 days after first immunization by administering i.p. $10 \mu \mathrm{g}$ of purified Ag85B produced in E. coli plus incomplete Freud's adjuvant $(20 \mu \mathrm{L})$ in PBS. Serum and feces samples were taken right before and 3 weeks after boosting.

\section{Antibody Analyses}

Antigen-specific total immunoglobulin $\mathrm{G}(\mathrm{IgG}), \mathrm{IgG}_{1}$ and $\mathrm{IgG}_{2 \mathrm{a}}$ levels in serum were measured by ELISA. Feces were collected and processed in cold the same day of sampling for mucosal IgA analysis. Briefly, feces were homogenized with the use of a pestle in 5\% milk in PBS with phenylmethylsulfonyl fluoride (PMSF, 1 mM, Sigma, St. Louis, MO) in 500 $\mu \mathrm{L}$ of buffer per $100 \mathrm{mg}$ of fecal material. Samples were vortexed and centrifuged at $7000 \mathrm{rpm}\left(4^{\circ} \mathrm{C}\right)$ for $10 \mathrm{~min}$. Supernatant collected was used as primary antibody in ELISA.

Purified Ag85B produced in E. coli was used to coat ELISA plates $(1 \mu \mathrm{g}$ per well $)$ and incubated overnight at $4{ }^{\circ} \mathrm{C}$. Plates were washed 3 times with PBST for $5 \mathrm{~min}$ and then blocked with 5\% defatted milk in PBST at $25^{\circ} \mathrm{C}$ for $2 \mathrm{~h}$. Plates were washed 3 times with PBST and the corresponding test sample (for sera, 1:160 dilution for IgG determination and 1:20 for IgG subclasses determination; for feces, $\operatorname{IgA}$ was measured directly in undiluted feces extract) was loaded and incubated at $37^{\circ} \mathrm{C}$ for $2 \mathrm{~h}$. Following 3 washes with PBST, the corresponding HRP-conjugated secondary antibody (1:2000) was added to each well and incubated at $37{ }^{\circ} \mathrm{C}$ for $2 \mathrm{~h}$. Plates were washed and immunodetection was revealed by adding a solution of OPD peroxidase substrate. Absorbance at $490 \mathrm{~nm}$ was measured in an iMark microplate reader (Bio-Rad, Hercules, CA, USA).

\section{Data Analysis}

Descriptive statistics were generated and means \pm standard deviations (SD) were calculated. One-way variance analysis (ANOVA) followed by Tukey multiple range test were used to compare means. Differences among means at $p<0.05$ were considered statistically significant. Sigma plot 11.0 software was used to perform all the statistical analysis.

\section{Results}

\section{Molecular Analysis and Antigen Immunoreactivity of the Alfalfa-made Antigen}

The $A g 85 B$ gene was successfully cloned into pMDC 32 as evidenced by PCR and sequencing conducted for the candidate clones (data not shown). Upon alfalfa genetic transformation (57.7\% transformation efficiency), a total of 100 embryos from antibiotic-resistant calli were rescued and transferred to a second selection round; where amorphous, vitrified, necrotic and not well-developed plants were discarded (Supplementary Fig. S1a). A total of 56 embryos were fully regenerated to plants (Supplementary Fig. S1b, c, d) and 25 alfalfa lines were selected for further analysis. Non-transformed explants (near isogenic WT plants) used as negative control did not grow in the presence of hygromycin (Supplementary Fig. S1a).

Based on the assay of callus induction, 21 lines were selected from the 25 lines analyzed (lines: 1-12, 14-20, and 23-24). Genomic DNA from the 21 selected alfalfa lines was extracted and transgenesis was confirmed in 19 plants $(1-12,14-20)$, which showed the expected $800 \mathrm{bp}$ amplicon and matched with that observed for the positive 


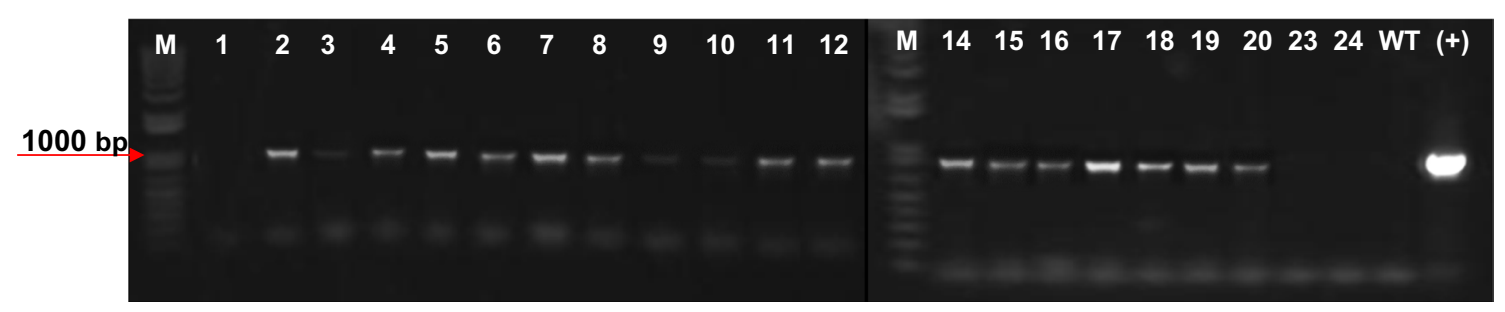

Fig. 2 Detection of the $A g 85 B$ gene in transformed alfalfa plants by PCR analysis. Reaction was performed with a pair of specific primers targeting the gene of interest to yield an 876 bp amplicon. M: $1 \mathrm{~Kb}$

control (Fig. 2). WT alfalfa used as negative control showed no amplicons. Negative alfalfa lines were discarded and the confirmed positive ones ( $n=19$ lines) were subcultured for biomass production and further determination of antigen expression levels.

During subsequent cultivation of the selected lines, some of them developed malformations and were discarded. In order to determinate the antigenic properties of the plant-made antigen, as well as to identify the higher expresser lines, an ELISA analysis using a serum from a MAP naturally infected animal was conducted. The highest Ag85B expression was observed in the line 20 with OD
Plus, 1-21: transformed lines, WT: Wild type (near isogenic control alfalfa), (+): Positive control for Ag85B gene (10 ng of pQE80L: Ag85B)

values that were almost twofold higher than those of the WT, followed by lines $4,6,19,12,17,11,2$ and 1 . The mean OD values of most of the positive alfalfa lines were 0.35 (or 0.16 after subtracting the OD values of the WT control plant), with line 14 near to the OD values of the WT plants (Fig. 3). Statistical analysis revealed significant differences in lines $1,2,4,6,11,12,17,19$ and 20 respect to the WT plant $(p=0.001)$. Line 20 accumulated up to $840 \mathrm{ng}$ Ag85B per gram of freeze-dried weight leaf tissue. Western blot analysis revealed an immunoreactive band of $\approx 32 \mathrm{kDa}$ (Fig. 4).

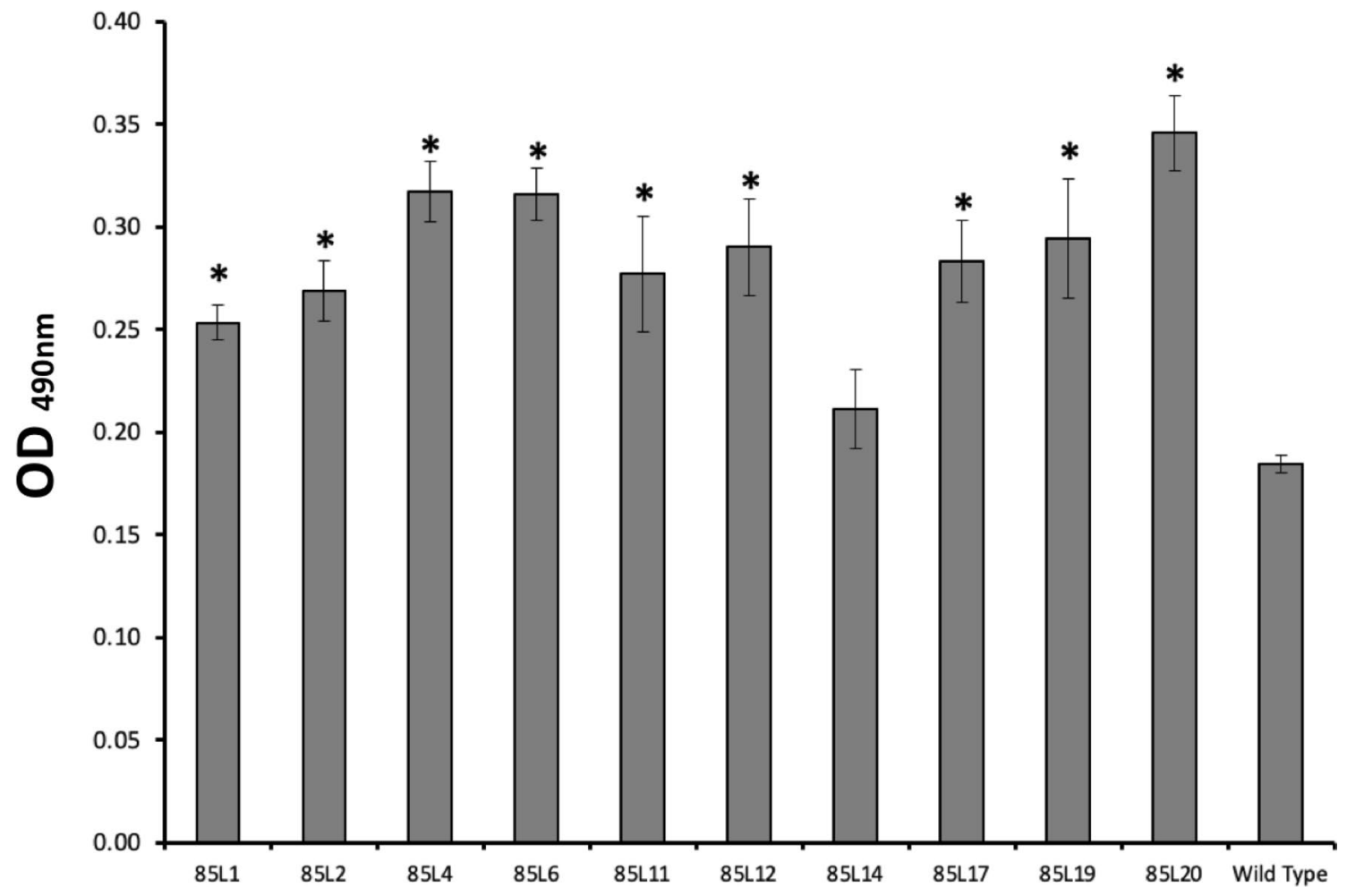

Fig. $3 \mathrm{Ag} 85 \mathrm{~B}$ detection in transgenic alfalfa lines by ELISA analysis using serum from a naturally infected animal with MAP for labeling. The absorbance from the near isogenic control alfalfa (WT) was subtracted (withdraw) from the values of the transgenic alfalfa lines. Statistical differences between transgenic alfalfa lines and WT are denoted by an asterisk (*). Alphanumeric keys were assigned to each transgenic plant by adding $85 \mathrm{~L}$ and the progressive number of obtained lines from 1 to 20 


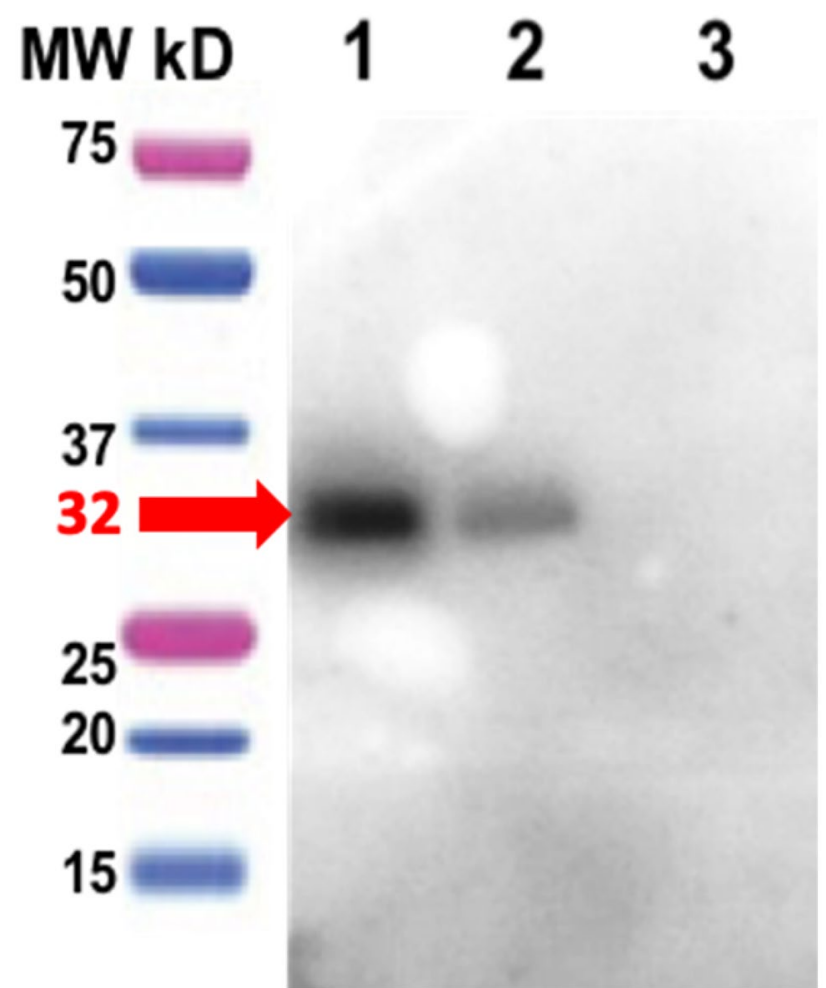

Fig. 4 Immunoreactivity of the alfalfa-made Ag85B antigen assessed by Western blot. Lane 1: Purified recombinant Ag85B (positive control, $250 \mathrm{ng}$ ); lane 2: Ag85B produced in transgenic alfalfa ( $105 \mathrm{ng}$ ); lane 3: Wild type (WT, near isogenic control alfalfa). Protein extracts were resolved by SDS-PAGE using 4-12\% acrylamide gels under denaturing conditions and transferred to PVDF membranes. Anti-Ag85B hyperimmune serum raised in mice was used for primary labeling

Line 20 was selected to further evaluate the reactivity of the plant-made $\mathrm{Ag} 58 \mathrm{~B}$ against sera samples from a group of animals naturally infected with MAP from Mexicali, Baja California, Mexico (Fig. 5). Serum \#8 showed the highest reactivity against the plant-made Ag85B with twofold OD values respect that of the WT control (Fig. 5). Statistical analysis showed significant differences between WT and the transgenic line when labeled with test serum \#8 ( $p<0.001)$.

\section{Immunogenicity of Transgenic Alfalfa Expressing MAP-Ag85B Without Adjuvant}

Since no other studies regarding the oral immunogenicity of plant-made MAP-Ag85B have been reported, a first approach to explore the immunogenic properties of the plant-made Ag85B was implemented by orally or subcutaneously immunizing mice with either transgenic or WT alfalfa plants. The systemic levels of the anti-Ag85B antibodies induced in test animals were determined by ELISA. Serum antibody IgG levels in orally immunized mice trended to increase after the first immunization (week 2), and dropped at week 4 (Supplemental Fig. S2a). Subcutaneous immunization led to no apparent difference between the OD values of plant-made Ag85B- and WT-treated groups (Supplemental Fig. S2b). The highest anti-Ag85B IgG levels for subcutaneous immunization reached at week 2 , whereas the orally immunized group reached the maximum anti-Ag85B $\mathrm{IgG}$ levels at week 3. Similarly, the IgG subclass analysis (IgG1 and IgG2a) showed a slight trend to increase at week 4, mainly for IgG2a (Supplemental Fig. S2c, d). However, statistical analysis showed no significant differences between groups treated with the plant-made Ag85B and WT plants.

\section{Immunogenicity of Transgenic Alfalfa Expressing MAP-Ag85B with Adjuvant}

In the previous experiment, transgenic alfalfa plants expressing Ag85B showed a tendency to induce a humoral immune response in orally immunized mice. To improve the immunogenicity of the test antigen, an oral immunization scheme based on the administration of the plant-made Ag85B plus $\mathrm{CT}$ as adjuvant was explored in a second experiment. Specific anti-Ag85B IgG levels increased in sera in the groups immunized with the plant-made Ag85B, with or without the use of CT (Fig. 6a). However, the increased response was only statistically significant $(p<0.05)$ in the group adjuvanted with $\mathrm{CT}$ at weeks 3 and 4 . Specific anti-85B antibody IgA levels were higher in feces from groups immunized with the plant-made Ag85B, with or without the use of CT. However, no statistically differences were detected compared to the WT control group (Fig. 6b).

\section{Long-term Immune Responses Analyses}

Since the plant-made Ag85B plus CT adjuvant induced significant humoral antibody responses, a long-term immune response analysis was conducted next. An i.p. boost with purified Ag85B plus incomplete Freud's adjuvant was given to mice at 180 days post-first oral immunization. It is known that priming by parenteral routes with purified antigens followed by a boosting by the oral route with a plant-made vaccine leads to an enhancement of both systemic and mucosal immunity. Higher systemic anti-Ag85B IgG levels were observed 3 weeks after the boost in the group immunized with the plant-made Ag85B (regardless of the use of $\mathrm{CT}$ as adjuvant) compared to control WT group (Fig. 7a $p$ $=0.004$ ). Similarly, anti-85B IgA levels in feces increased 3 weeks after the boost in groups immunized with the plantmade Ag85B with respect to the control WT group (Fig. 7b, $p=0.001$ ). 


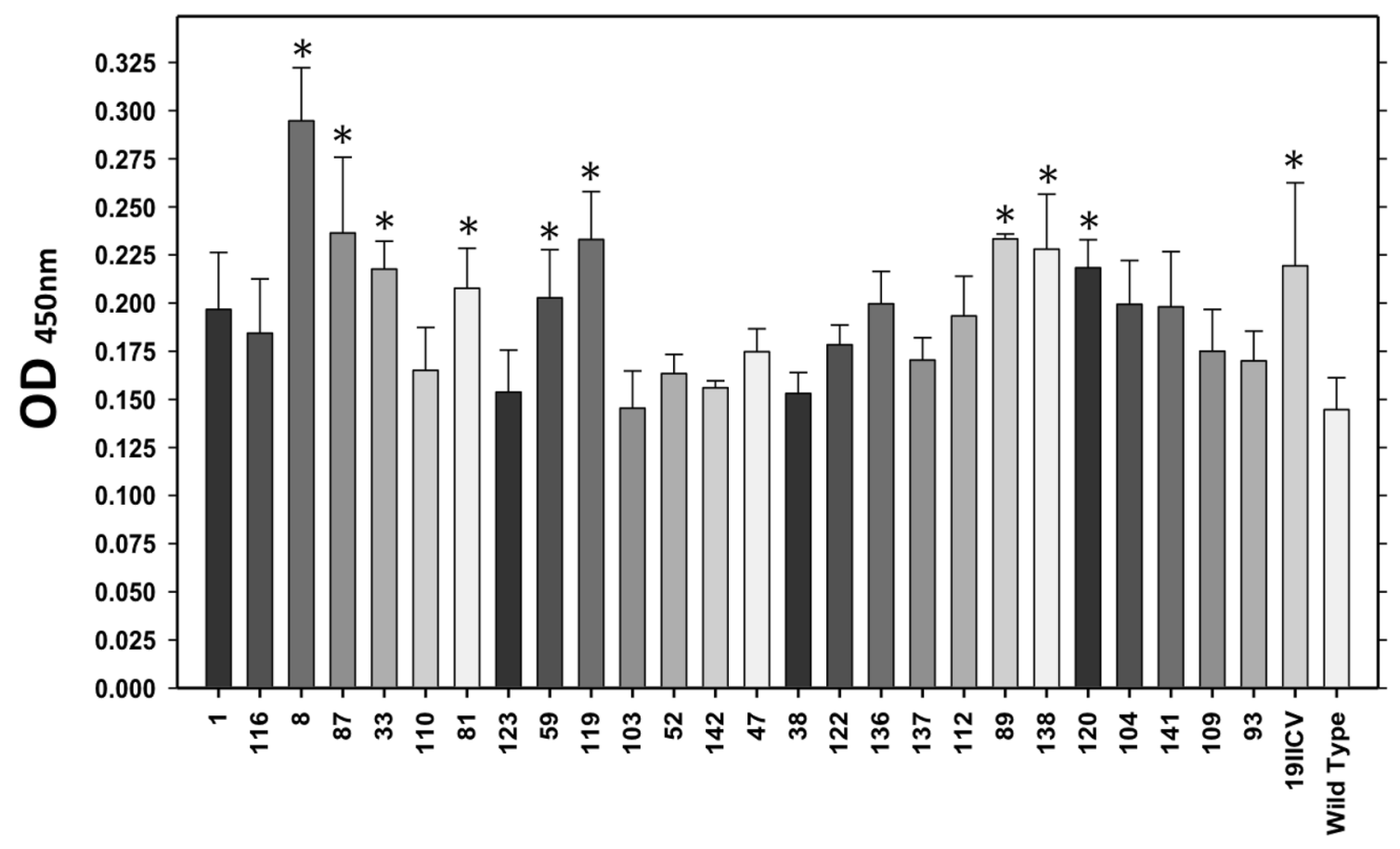

Fig. 5 Antigenicity of the alfalfa-made Ag85B. ELISA was applied to transgenic alfalfa line (\#20) expressing the highest amount of recombinant $\mathrm{Ag} 85 \mathrm{~B}$. Primary labeling was performed with sera from animals naturally infected with MAP (1:25 dilution; provided by the

\section{Discussion}

MAP generates severe economic losses in the dairy industry in terms of reduced milk production and premature culling [18]. In the present report the 85B antigen from MAP was produced in alfalfa plants for the first time and tested as oral vaccine candidate. Alfalfa is the highest yielding crop of the temperate forage legumes and lacks mammalian toxins, pathogens, or allergens. This plant species has been used by other groups to develop subunit vaccines against several pathogens [9-15, 44]. Herein, following $A$. tumefaciens - mediated transformation, 50 somatic embryos were rescued in the second selection round. Selection of transgenic plants consisted in discarding amorphous, vitrified, or necrotic plants, whereas viable transgenic plants were selected for propagation. Twenty-five transgenic lines were initially established and 21 were positive for the callus induction assay under selective pressure and 19 subsequently confirmed by PCR.

Several protocols for efficient transformation/regeneration of alfalfa are available [12, 45, 46], leading to variable transformation efficiencies; which is basically associated to the alfalfa variety $[47,48]$, the specific DNA sequences introduced [48] and the A. tumefaciens strain used [49]. Transformation efficiency for alfalfa hybrid RSY27, which is a rapid regenerative variety, using Agrobacterium strain LBA4404
Autonomous University of Baja California, Mexicali, Baja California, México). Protein samples from near isogenic control alfalfa plants (WT) were labeled with serum from the MAP-infected animal \#8

led to a $57.7 \%$ efficiency for the $\mathrm{Ag} 85 \mathrm{~B}$ gene in a 3-month period, which is higher than to those reported in alfalfa and other plants using A. tumefaciens-mediated transformation [50-52]. Therefore, we propose this as a useful protocol for the development of other plant-based vaccine candidates. Ag85B expression levels determined by ELISA reached up to $840 \mathrm{ng}$ per gram of dry weight leaf tissue $(0.062 \% \mathrm{TSP})$. These levels are similar to those attained for other proteins expressed in plants, 0.1\% TSP of F4 fimbrial adhesin FaeG in Alfalfa (Medicago sativa L.) [53], 0.1-0.2\% TSP of Spike (S) protein of transmissible gastroenteritis virus in Tobacco plants (Nicotiana tabacum) [54] or $0.1 \%$ of structural protein VP60 produced in Potato (Solanum tuberosum) [55]. The difference in protein yields among the modified plants lines may be associated to diverse factors, such as differential transgene copy number and insertion sites along the plant genome, owing to the non-specific and no-homologous random recombination mediated by A. tumefaciens [56].

The antigenicity of the alfalfa-made Ag85B was successfully evidenced by the reactivity against sera from naturally infected animals and hyperimmune sera from mice immunized with the purified antigen, suggesting the preservation of the antigenic determinants in the plant-made antigen. Thus, oral immunization of MAP antigens was conducted because this constitutes the ideal route considering that the pathogen infects the gastrointestinal tract [20]. 
Fig. 6 Anti-85B antibody levels in sera (a, IgG) and feces (b, $\operatorname{IgA}$ ) from orally treated mice with wild type (WT) or transgenic alfalfa expressing Ag85B plus $C T$ adjuvant $(85 \mathrm{~B}+\mathrm{CT})$. $\mathrm{BALB} / \mathrm{c}$ mice were immunized on days $0,7,15$, and 24 with $100 \mathrm{mg}$ wild type alfalfa in PBS by the oral route (i), or $100 \mathrm{mg}$ transgenic alfalfa expressing Ag85B in PBS plus cholera toxin $(10 \mu \mathrm{g}$ CT, Sigma) by the oral route (ii). Antigen-specific total immunoglobulin $\mathrm{G}$ a and A b levels were measured in serum and feces samples by ELISA. Purified Ag85B antigen was used to coat ELISA plates (1 $\mu \mathrm{g}$ per well)
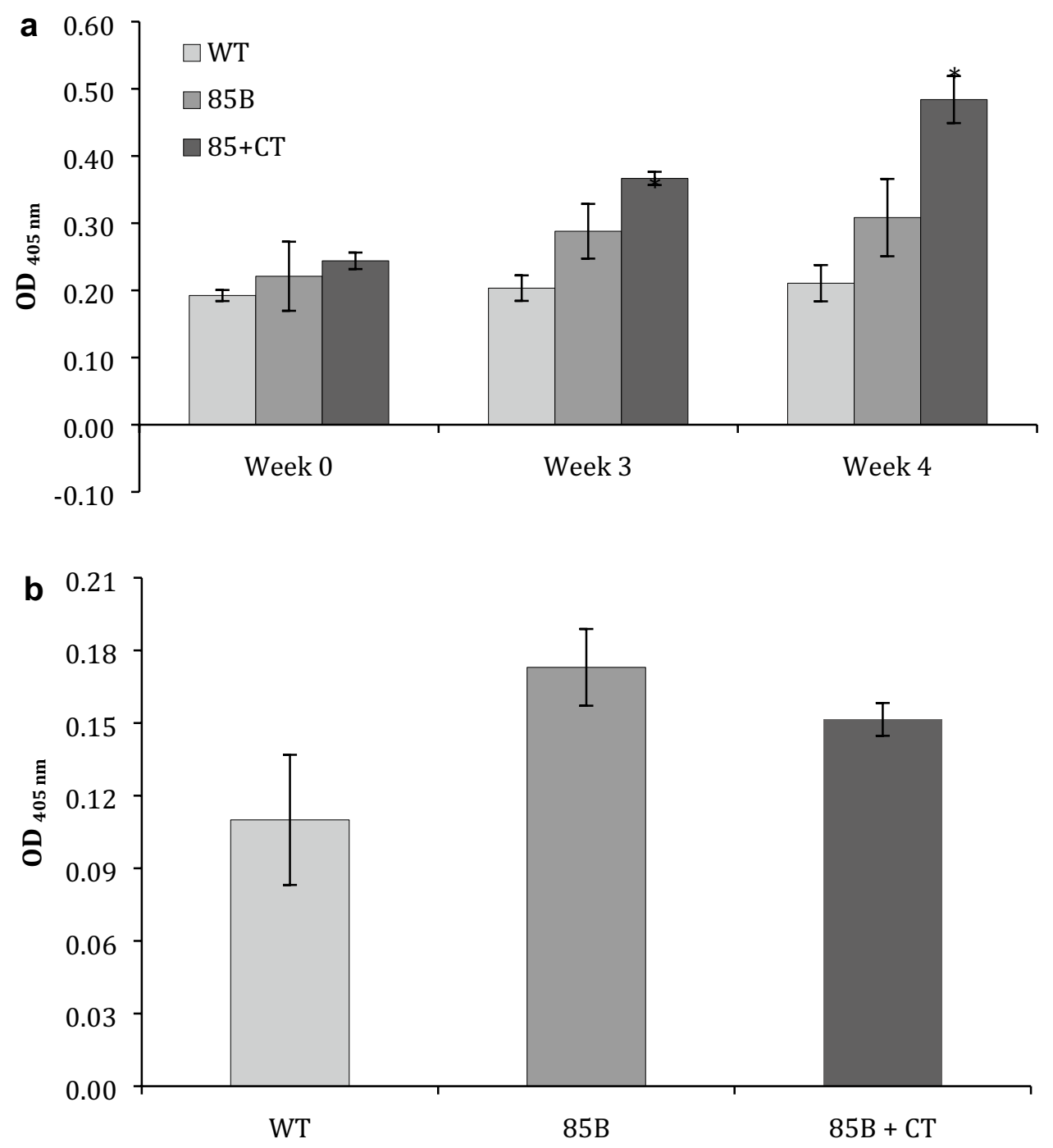

The mycobacterial proteins able to induce host's immune responses are produced in the early growth stage of the bacteria, from which Ag85B is the most secreted protein [57]. In fact, Ag85B from M. tuberculosis is considered by itself both strong antigen and adjuvant of vaccines, which justify its use as an excellent subunit vaccine candidate [58]. Moreover, M. tuberculosis Ag85B fused to elastin-like peptides was expressed in tobacco plants and proved immunogenic for piglets [30]. We first explored the systemic antibody levels induced in mice by the plant-made Ag85B. The mouse is a biological model commonly used to study virulence and host pathogen interactions of various infectious microorganisms including mycobacteria, it is able to provide important insights [59-61]. In this sense, several authors have used strains of mice for studying mycobacterial infections, such as susceptible strains or genetically modified animals lacking specific components of the immune system allowing defined experimentation to understand the role of critical mycobacterial factors or host components involved in pathogenesis [60-62].

The results indicated that humoral responses increased but they were not statistically significant, whereas the IgG1/IgG2a ratio had not an apparent polarization to Th1 response. Therefore, a further characterization of the intestinal and systemic humoral immune responses induced by the alfalfa-made Ag85B when co-administered with a mucosal adjuvant was performed to better characterize the properties of this vaccine. Anti-Ag85B IgG levels increased in serum from groups immunized with the plant-made Ag85B plus $\mathrm{CT}$ at week 3 and 4 post-first immunization, whereas anti85B antibody IgA levels were higher in feces from groups immunized with plant-made Ag85B, but no statistical differences were observed. Interestingly, the long-term immunity analysis demonstrated that mice immunized with the 
Fig. 7 Long-term immune response of orally immunized mice with transgenic alfalfa expressing Ag85B. BALB/c mice were immunized on days 0, 7, 15 and 24: (i) $100 \mathrm{mg}$ wild type alfalfa in PBS by the oral route, and (ii) $100 \mathrm{mg}$ transgenic alfalfa expressing Ag85B in PBS plus cholera toxin (10 $\mu \mathrm{g}$ CT, Sigma) by the oral route, and a boost was administrated with purified recombinant Ag85B + Incomplete Freud adjuvant $(20 \mu \mathrm{L})$ by i.p route at day 180 after first immunization (indicated as $85 \mathrm{~B}+\mathrm{CT}$ group). Antigen-specific total immunoglobulin $\mathrm{G}$ a and immunoglobulin A b levels were measured in serum and feces samples by ELISA. Purified Ag85B antigen was used to coat ELISA plates (1 $\mu \mathrm{g}$ per well)
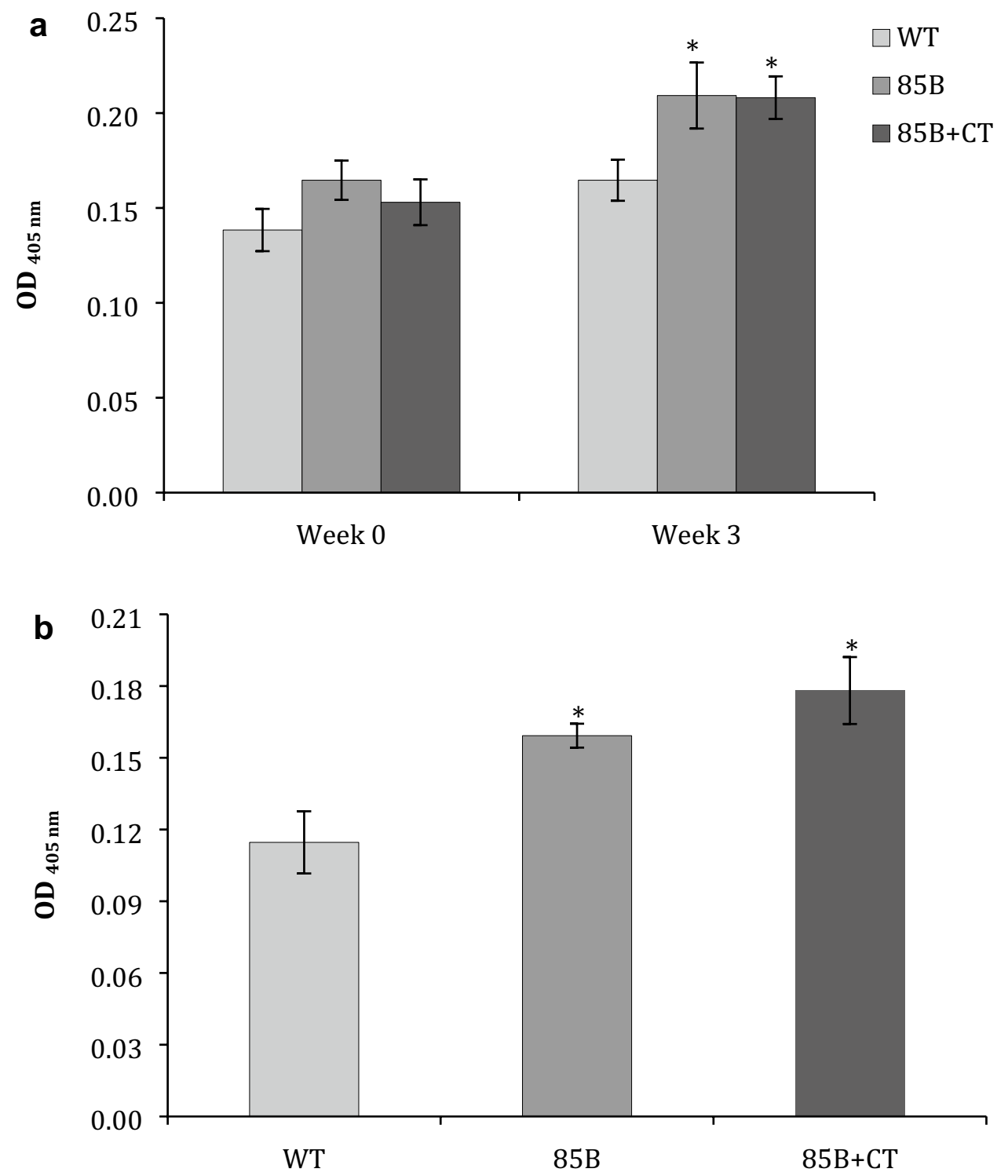

plant-made Ag85B induced significant levels of anti-85B IgG in serum and anti-85B $\operatorname{IgA}$ in feces 3 weeks after the boost. The improved responses to Ag85B associated to the co-administration of CT is in agreement with the well-characterized adjuvant effects exerted by CT or its B subunit in oral subunit vaccine formulations, in terms on the induction of stronger, long-term humoral responses at both the systemic and mucosal levels [58, 63, 64]. The CT mucosal adjuvant effects have been associated to (i) the GM1-ganglioside binding activity, which favors the uptake by $\mathrm{M}$ cells and antigen processing cells; and (ii) the ADP-ribosyltransferase activity of it is a subunit. In the case of plant-made vaccines, the B subunit of this type of bacterial toxins have been used as antigens to protect against the corresponding enteric pathogen or fused to unrelated antigens to induce immunity against other diseases [65-67]. Interestingly, the stimulation of mucosal secretory $\operatorname{IgA}$ against virulence determinants of Mycobacterium sp. is also desired to prevent the attachment and/or colonization of the pathogen onto the mucosal surface or neutralize surface acting toxins [68, 69]. Moreover, booster doses may allow the maintenance of mucosal IgA responses [70].

In line with our findings, Mycobacterium tuberculosis antigens have been produced in some plant species. For instance, Ag85B from M. tuberculosis fused to ESAT-6 was successfully expressed in $N$. benthamiana at yields up to of $800 \mathrm{mg} / \mathrm{kg}$ of fresh leaf weight, which was recognized by specific antibodies as revealed by western blot [31]. Also, Ag85B of M. tuberculosis fused with the ESAT-6 antigen and the elastin-like peptide (ELP) was successfully 
expressed in tobacco (4\% TSP) and was able to induce humoral responses in mice (purified plant-made protein) and piglets (crude plant extracts) [30]. In another study, potatomade Ag85B, MPT83, MPT64, and ESAT-6 antigens from M. tuberculosis induced high titers of $\mathrm{IgG}$ and $\mathrm{IgA}$ as well as Th1-cytokines (IFN- $\gamma$ and IL-2) in mice orally immunized with a pool of all the transgenic plants; however, the response was lower for $\mathrm{Ag} 85 \mathrm{~B}$ when evaluated individually [70]. Interestingly, M. tuberculosis Ag85B was expressed in tobacco in the form of a recombinant immune complex with the latency-associated Acr antigen of M. tuberculosis and fused to the heavy chain of a monoclonal antibody; the plant-made antigens were immunogenic in terms of the production of antigen-specific $\operatorname{IgG}$ antibodies in the serum of intranasally-immunized animals and the production of key cytokines (IFN- $\gamma$, IL-2, and TNF- $\alpha$ ) in stimulated splenocytes, and the reduction of $M$. tuberculosis infection burden in the lungs [71]. In line with these precedents, our findings support the production of $\mathrm{Ag} 85 \mathrm{~B}$ from MAP preserving its antigenicity and the ability to induce humoral responses upon oral administration in mice, a well-established animal model for paratuberculosis (Johne's diseases) [72].

Alfalfa lines expressing MAP-Ag85B have been efficiently generated, which constitute the first model of a plant-based vaccine targeting Mycobacterium avium subsp. paratuberculosis. The assessment of the immunogenicity and the ability to induce long-term immune responses of the alfalfa-made $\mathrm{Ag} 85 \mathrm{~B}$ antigen opens the path for a detailed characterization of the properties of this candidate vaccine to fight against MAP. In the near future, pathogen challenges to analyze protective efficacy and a boost of the plant-made vaccine by the oral route to evaluate the long-term immune response.

Supplementary Information The online version contains supplementary material available at https://doi.org/10.1007/s12033-021-00307-w.

Acknowledgements Biol. Rodrigo Celis García for technical assistance. Current investigations are supported by the Consejo Nacional de Ciencia y Tecnología (CONACYT), Mexico, and UASLP, Mexico (Grants INFR-2014-01-225843 and FAI/UASLP/2015 to S.R.M.; Grants CB-2010-01-151818, INFR- 2014-01-225924 to CA).

\section{Compliance with Ethical Standards}

Conflict of interest The authors declare that they have no conflict of interest.

\section{References}

1. Makhzoum, A., Benyammi, R., Moustafa, K., \& TrémouillauxGuiller, J. (2014). Recent advances in host plants and expression cassettes' structure and function in plant molecular pharming. BioDrugs, 28, 145-159.

2. Rosales-Mendoza, S., Angulo, C., \& Meza, B. (2016). FoodGrade Organisms and Oral Delivery Vehicles. Trends Biotechnology, 34, 124-136.

3. Rybicki, E. P. (2017). Plant-made vaccines and reagents for the one health initiative. Human Vaccines and Immunotherapeutics, 13, 2912-2917.

4. Hernández, M., Rosas, G., Cervantes, J., Fragoso, G., RosalesMendoza, S., \& Sciutto, E. (2014). Transgenic plants: a 5-year update on oral antipathogen vaccine development. Expert Review Vaccines, 13, 1523-1536.

5. Rosales-Mendoza, S., \& Salazar-González, J. A. (2014). Immunological aspects of using plant cells as delivery vehicles for oral vaccines. Expert Review Vaccines, 13, 737-749.

6. Chan, H. T., \& Daniell, H. (2015). Plant-made oral vaccines against human infectious diseases -Are we there yet? Plant Biotechnology Journal, 13, 1056-1070.

7. Murad, S., Fuller, S., Menary, J., Moore, C., Pinneh, E., Szeto, T., et al. (2020). Molecular Pharming for low and middle income countries. Current Opinion in Biotechnology, 61, 53-59.

8. Erickson, L., Yu, W. J., Brandle, J., \& Rymerson, R. (2002). Molecular farming of plants and animals for human and veterinary medicine. Kluwer academic publishers, The Netherlands. Chapter, 2, 33-47.

9. Dong, J. L., Liang, B. G., Jin, Y. S., Zhan, W. J., \& Wang, T. (2005). Oral immunization with pBsVP6-transgenic alfalfa protects mice against rotavirus infection. Virology, 339, 153-163.

10. Dus Santos, M. J., Carrillo, C., Ardila, F., Ríos, R. D., Franzone, P., Piccone, M. E., et al. (2005). Development of transgenic alfalfa plants containing the foot and mouth disease virus structural polyprotein gene P1 and its utilization as an experimental immunogen. Vaccine, 23, 1838-1843.

11. Dus Santos, M. J., Wigdorovitz, A., Trono, K., Rios, R. D., Franzone, P. M., Gil, F., et al. (2002). A novel methodology to develop a foot and mouth disease virus (FMDV) peptide-based vaccine in transgenic plants. Vaccine, 20, 1141-1147.

12. Joensuu, J. J., Verdonck, F., Ehrström, A., Peltola, M., SiljanderRasi, H., Nuutila, A. M., et al. (2006). F4 (K88) fimbrial adhesin FaeG expressed in alfalfa reduces F4+ enterotoxigenic Escherichia coli excretion in weaned piglets. Vaccine, 24, 2387-2394.

13. Lee, R. W. H., Cornelisse, M., Ziauddin, A., Slack, P. J., Hodgin, D. C., Strommer, J. N., et al. (2008). Expression of a modified Mannheimia haemolytica GS60 outer membrane lipoprotein in transgenic alfalfa for the development of an edible vaccine against bovine pneumonic pasteurellosis. Journal of Biotechnology, 135, 224-231.

14. Pérez Aguirreburualde, M. S., Gómez, M. C., Ostachuk, A., Wolman, F., Albanesi, G., Pecora, A., et al. (2013). Efficacy of a BVDV subunit vaccine produced in alfalfa transgenic plants. Veterinary Immunology Immunopathology, 151, 315-324.

15. Wigdorovitz, A., Carrillo, C., Dus Santos, M. J., Trono, K., Peralta, A., Gomez, M. C., et al. (1999). Induction of a protective antibody response to foot and mouse disease virus in mice following oral or parenteral immunization with alfalfa transgenic plants expressing the viral structural protein VP1. Virology, 225, 347-353.

16. Wigdorovitz, A., Mozgovoj, M., Dus Santos, M. J., Parreno, V., Gomez, C., Perez-Filgueira, D. M., et al. (2004). Protective lactogenic immunity conferred by an edible peptide vaccine to bovine rotavirus produced in transgenic plants. Journal of General Virology, 85, 1825-1832.

17. Bates, A., O'Brien, R., Liggett, S., \& Griffin, F. (2019). Control of Mycobacterium avium subsp paratuberculosis infection on a New Zealand pastoral dairy farm. BMC Veterinary Research, 15(1), 266. 
18. Whittington, R., Donat, K., Weber, M. F., Kelton, D., Nielsen, S. S., Eisenberg, S., et al. (2019). Control of paratuberculosis: who, why and how A review of 48 countries. BMC Veterinary Research, 15(1), 198.

19. Momotani, E., Whipple, D. L., Thiermann, A. B., \& Cheville, N. F. (1988). Role of M cells and macrophages in the entrance of Mycobacterium paratuberculosis into domes of ileal Peyer's patches in calves. Veterinary Pathology, 25, 131-137.

20. Gupta, S., Singh, S. V., Singh, M., Chaubey, K. K., Karthik, K., Bhatia, A. K., et al. (2019). Vaccine approaches for the'therapeutic management'of Mycobacterium avium subspecies paratuberculosis infection in domestic livestock. Veterinary Quarterly, 39(1), 143-152.

21. Eppleston, J., \& Windsor, P. A. (2007). Lesions attributed to vaccination of sheep with Gudair for the control of ovine paratuberculosis: post farm economic impacts at slaughter. Australian Veterinary Journal, 85, 129-133.

22. Stabel, J. R., Waters, W. R., Bannantine, J. P., \& Lyashchenko, K. (2011). Mediation of host immune responses after immunization of neonatal calves with a heat-killed Mycobacterium avium subsp. paratuberculosis vaccine. Clinic Vaccine Immunology, 18, 2079-2089.

23. Kaufmann, S. H., Weiner, J., \& von Reyn, C. F. (2017). Novel approaches to tuberculosis vaccine development. International Journal of Infectious Diseases, 56, 263-267.

24. Mullerad, J., Michal, I., Fishman, Y., Hovav, A. H., Barletta, R. G., \& Bercovier, H. (2002). The immunogenicity of Mycobacterium paratuberculosis 85B antigen. Medical Microbiology and Immunology, 190, 179-187.

25. Shin, S. J., Chang, C. F., Chang, C. D., McDonough, S. P., Thompson, B., Yoo, H. S., et al. (2005). In Vitro Cellular Immune Responses to Recombinant Antigens of Mycobacterium avium subsp. paratuberculosis. Infection and Immunity, 73, 5074-5085.

26. Rosseels, V., Marché, S., Roupie, V., Govaerts, M., Godfroid, J., Walravens, K., et al. (2006). Members of the 30- to 32-Kilodalton Mycolyl Transferase Family (Ag85) from Culture Filtrate of Mycobacterium avium subsp. paratuberculosis Are Immunodominant Th1-Type Antigens Recognized Early upon Infection in Mice and Cattle. Infection and Immunity, 74, 202-212.

27. Kathaperumal, K., Kumanan, V., McDonough, S., Chen, L. H., Park, S. U., Moreira, M. A. S., et al. (2009). Evaluation of immune responses and protective efficacy in goat model following immunization with coctail of recombinant antigens and a polyprotein of Mycobacterium avium subsp. paratuberculosis. Vaccine, 27, 123-135.

28. Mikkelsen, H., Aagaard, C., Nielsel, S. S., \& Jungersen, G. (2011). Novel antigens for detection of cell mediated immune responses to Mycobacterium avium subsp. paratuberculosis infection in cattle. Veterinary Immunology and Immunopathology, 143, 46-54.

29. Thakur, A., Aagaard, C., Stockmarr, A., Andersen, P., \& Jungersen, G. (2013). Cell-mediated and humoral immune response after immunization of calves with a recombinant multiantigenic Mycobacterium avium subsp. paratuberculosis subunit vaccine at different ages. Clinic Vaccine Immunology, 20, 551-558.

30. Floss, D. M., Mockey, M., Zanello, G., Brosson, D., Diogon, M., Frutos, R., et al. (2010). Expression and Immunogenicity of the Mycobacterial Ag85B/ESAT-6 Antigens Produced in Transgenic Plants by Elastin-Like Peptide Fusion Strategy (p. 274346). Article ID: Journal Biomedicine Biotechnology.

31. Dorokhov, Y. L., Sheveleva, A. A., Frolova, O. Y., Komarova, T. V., Zvereva, A. S., Ivanov, P. A., et al. (2007). Superexpression of tuberculosis antigens in plant leaves. Tuberculosis, 87, 218-224.

32. Matvieieva, N. A., Vasylenko, M. Y., Shakhovsky, A. I., \& Kuchuk, N. V. (2009). Agrobacterium-mediated transformation of lettuce (Lactuca sativa L.) with genes coding bacterial antigens from Mycobacterium tuberculosis. Cytology and Genetics, 43, $27-32$.

33. Rigano, M. M., Alvarez, M. L., Pinkhasov, J., Jin, Y., Sala, F., Arntzen, C. J., et al. (2004). Production of a fusion protein consisting of the enterotoxigenic Escherichia coli heat-labile toxin B subunit and a tuberculosis antigen in Arabidopsis thaliana. Plant Cell Report, 22, 502-508.

34. Rigano, M. M., Dreitz, S., Kipnis, A.-P., Izzo, A. A., \& Walmsley, A. M. (2006). Oral immunogenicity of a plant-made subunit, tuberculosis vaccine. Vaccine, 24, 691-695.

35. Zelada, A. M., Calamante, G., de la Paz Santangelo, M., Bigi, F., Verna, F., Mentaberry, A., et al. (2006). Expression of tuberculosis antigen ESAT-6 in Nicotiana tabacum using a potato virus X-based vector. Tuberculosis, 86, 263-267.

36. Saba, K., Sameeullah, M., Asghar, A., Gottschamel, J., Latif, S., Lössl, A. G., et al. (2020). Expression of ESAT-6 antigen from Mycobacterium tuberculosis in broccoli: An edible plant. Biotechnology and Applied Biochemistry, 67, 148-157.

37. Saba, K., Gottschamel, J., Younus, I., Syed, T., Gull, K., Lössl, A. G., et al. (2019). Chloroplast-based inducible expression of ESAT-6 antigen for development of a plant-based vaccine against tuberculosis. Journal of Biotechnology, 305, 1-10.

38. Lakshmi, P. S., Verma, D., Yang, X., Lloyd, B., \& Daniell, H. (2013). Low cost tuberculosis vaccine antigens in capsules: expression in chloroplasts, bio-encapsulation, stability, and functional evaluation in vitro. PLOS ONE, 8, e54708. https:// doi.org/10.1371/journal.pone.0054708.

39. Samac, D. A., \& Austin-Phillips, S. (2006). Alfalfa (Medicago sativa L.). Methods in Molecular Biology, 343, 301-311.

40. Celis-García, R. (2012) Transformación genética de Alfalfa (Medicago sativa L.) mediada por Agrobacterium tumefaciens como sistema de producción de vacunas utilizando los genes MAP1609c (Ag85b) y MAP0586c de Mycobacterium avium subsp. paratuberculosis. Thesis. Escuela Nacional de Ciencias Biológicas. México.

41. Weigel, D., \& Glazebrook, J. (2002). Arabidopsis: A laboratory Manual. Cold Spring Harbor, NY: Cold Spring Harbor Laboratory Press.

42. Aguilar, O., Glatz, C. E., \& Rito-Palomares, M. (2009). Characterization of green-tissue protein extract from alfalfa (Medicago sativa) exploiting a 3-D technique. Journal of Separation Science, 32, 3223-3231.

43. Monreal-Escalante, E., Govea-Alonso, D. O., Hernández, M., Cervantes, J., Salazar-González, J. A., Romero-Maldonado, A., et al. (2016). Towards the development of an oral vaccine against porcine cysticercosis: expression of the protective HP6/TSOL18 antigen in transgenic carrots cells. Planta, 243, 675-685.

44. Legocki, A. B., Miedzinska, K., Czaplińska, M., Płucieniczak, A., \& Wedrychowicz, H. (2005). Immunoprotective properties of transgenic plants expressing E2 glycoprotein from CSFV and cysteine protease from Fasciola hepatica. Vaccine, 23, 1844-1846.

45. Tian, L., Wang, H., Wu, K., Latoszek-Green, M., Hu, M., Miki, B., et al. (2002). Efficient recovery of transgenic plants through organogenesis and embryogenesis using cryptic promoter to drive marker expression. Plant Cell Report, 20, 1181-1187.

46. Liu, W., Liang, Z., Wang, X., Sibbald, S., Hunter, D., \& Tian, L. (2013). Preservation and Faithful Expression of Transgene via Artificial Seeds in Alfalfa. PLOS ONE, 8, e56699. https://doi. org/10.1371/journal.pone.0056699.

47. Du, S., Erickson, L., \& Bowley, S. (1994). Effect of plant genotype on the transformation of cultived alfalfa (Medicago sativa) by Agrobacterium tumefaciens. Plant Cell. Report, 13, 330-334.

48. Desgagnés, R., Laberge, S., Allard, G., Khoudi, H., Castonguay, Y., Lapointe, J., et al. (1995). Genetic transformation of 
commercial breeding lines of alfalfa (Medicago sativa). Plant Cell, Tissue and Organ Culture, 42, 129-140.

49. Samac, D. A. (1995). Strain specificity in transformation of alfalfa by Agrobacterium tumefaciens. Plant Cell, Tissue and Organ Culture, 43, 271-277.

50. Ribas, F. B., Dechamp, E., Champion, A., Bertrand, B., Combes, M. C., Verdeil, J. L., et al. (2011). Agrobacterium-mediated genetic transformation of Coffea arabica (L.) is greatly enhanced by using established embryogenic callus cultures. BMC Plant Biology, 11, 92.

51. Ziauddin, A., Lee, R. W. H., Lo, R., Shewen, P., \& Strommer, J. (2004). Transformation of alfalfa with a bacterial fusion gene, Mannheimia haemolytica A1 leukotoxin50-gfp: Response with Agrobacterium tumefaciens strains LBA4404 and C58. Plant Cell, Tissue and Organ Culture, 79, 271-278.

52. Zhang, H., Huang, Q., \& Su, J. (2010). Development of Alfalfa (Medicago sativa L.) Regeneration System and AgrobacteriumMediated Genetic Transformation. Agricultural Sciences in China, 9, 170-178.

53. Joensuu, J. J., Verdonck, F., Ehrstrom, A., Peltola, M., SiljanderRasi, H., Nuutila, A. M., et al. (2006). F4 (K88) fimbrial adhesin FaeG expressed in alfalfa reduces F4+ enterotoxigenic Escherichia coli excretion in weaned piglets. Vaccine, 24, 2387-2394.

54. Tuboly, T., Yu, W., Bailey, A., Degrandis, S., Du, S., Erickson, L., \& Nagy, E. (2000). Immunogenicity of porcine transmissible gastroenteritis virus spike protein expressed in plants. Vaccine, 18, 2023-2028.

55. Castanon, S., Marin, M. S., Martin-Alonso, J. M., Boga, J. A., Casais, R., Humara, J. M., et al. (1999). Immunization with potato plants expressing VP60 protein protects against rabbit hemorrhagic disease virus. Journal of Virology, 1999(73), 4452-4455.

56. Kim, S.-I., Veena, S., \& Gelvin, B. (2007). Genome-wide analysis of Agrobacterium T-DNA integration sites in the Arabidopsis genome generated under non-selective conditions. The Plant Journal, 51(5), 779-791.

57. Huygen, K. (2014). The immunodominant T-cell epitopes of the mycolyl-transferases of the antigen 85 complex of M. tuberculosis. Frontiers in Immunology, 5, 321.

58. Rosales-Mendoza, S., Soria-Guerra, R. E., López-Revilla, R., Moreno-Fierros, L., \& Alpuche-Solís, A. G. (2008). Ingestion of transgenic carrots expressing the Escherichia coli heat-labile enterotoxin B subunit protects mice against cholera toxin challenge. Plant Cell Report, 27, 79-84.

59. Hines, M. E., 2nd., Stabel, J. R., Sweeney, R. W., Griffin, F., Talaat, A. M., Bakker, D., et al. (2007). Experimental challenge models for Johne's disease: a review and proposed international guidelines. Veterinary Microbiology, 122(3-4), 197-222.

60. Cooper, A. M. (2014). Mouse model of tuberculosis. Cold Spring Harbor Perspectives in Medicine, 5(2), a018556.

61. Begg, D. J., \& Whittington, R. J. (2008). Experimental animal infection models for Johne's disease, an infectious enteropathy caused by Mycobacterium avium subsp paratuberculosis. Veterinary Journal, 176(2), 129-145.
62. Abdissa, K., Ruangkiattikul, N., Ahrend, W., Nerlich, A., Beineke, A., Laarmann, K., et al. (2020). Relevance of inducible nitric oxide synthase for immune control of Mycobacterium avium subspecies paratuberculosis infection in mice. Virulence, 11(1), 465-481.

63. Granell, A., Fernández del-Carmen, A., \& Orzáez, D. (2010). In planta production of plant derived and non-plant-derived adjuvants. Expert Review of Vaccines, 9, 843-858.

64. Kim, M. Y., Kim, B. Y., Oh, S. M., Reljic, R., Jang, Y. S., \& Yang, M. S. (2016). Oral immunization of mice with transgenic rice calli expressing cholera toxin B subunit fused to consensus dengue cEDIII antigen induces antibodies to all four dengue serotypes. Plant Molecular Biology, 92, 347-356.

65. Rosales-Mendoza, S., Alpuche-Solís, Á. G., Soria-Guerra, R. E., Moreno-Fierros, L., Martínez-González, L., \& Herrera-Díaz, A. (2009). Expression of an Escherichia coli antigenic fusion protein comprising the heat labile toxin B subunit and the heat stable toxin, and its assembly as a functional oligomer in transplastomic tobacco plants. The Plant Journal, 57(1), 45-54.

66. Pillet, S., Aubin, É., Trépanier, S., Poulin, J. F., Yassine-Diab, B., ter Meulen, J., et al. (2018). Humoral and cell-mediated immune responses to $\mathrm{H} 5 \mathrm{~N} 1$ plant-made virus-like particle vaccine are differentially impacted by alum and GLA-SE adjuvants in a Phase 2 clinical trial. Vaccines, 3(1), 1-9.

67. Malm, M., Diessner, A., Tamminen, K., Liebscher, M., Vesikari, T., \& Blazevic, V. (2019). Rotavirus VP6 as an adjuvant for bivalent norovirus vaccine produced in Nicotiana benthamiana. Pharmaceutics, 11(5), 229.

68. Monreal-Escalante, E., Ramos-Vega, A. A., Salazar-González, J. A., Bañuelos-Hernández, B., Angulo, C., \& Rosales-Mendoza, S. (2017). Expression of the VP40 antigen from the Zaire ebolavirus in tobacco plants. Planta, 246, 123-132.

69. Abebe, F. (2019). Synergy between Th1 and Th2 responses during Mycobacterium tuberculosis infection: A review of current understanding: The paper discusses the importance of simultaneous induction of Th1/Th2 responses to design and develop vaccine against TB. International Reviews of Immunology, 38(4), 172-179.

70. Zhang, Y., Chen, S., Li, J., Liu, Y., Hu, Y., \& Cai, H. (2012). Oral immunogenicity of potato-derived antigens of Mycobacterium tuberculosis in mice. Acta Biochimica et Biophysica Sinica, 44, 823-830.

71. Pepponi, I., Diogo, G. R., Stylianou, E., van Dolleweerd, C. J., Drake, P. M. W., Paul, M. J., et al. (2014). Plant-derived recombinant immune complexes as self-adjuvanting TB immunogens for mucosal boosting of BCG. Plant Biotechnology Journal, 12, 840-850.

72. Hines, M. E., Stabel, J. R., Sweeney, R. W., Griffin, F., Talaat, A. M., Bakker, D., et al. (2007). Experimental challenge models for Johne's disease: a review and proposed international guidelines. Veterinary Microbiology, 122, 197-222.

Publisher's Note Springer Nature remains neutral with regard to jurisdictional claims in published maps and institutional affiliations. 